\title{
ANALYSIS AND DESIGN OF TWO FLYBACK-BASED INTEGRATED CONVERTERS FOR THE IMPLEMENTATION OF LFSW ELECTRONIC BALLASTS
}

\author{
Tiago B. Marchesan ${ }^{1}$, Marco Dalla Costa ${ }^{2}$, Marina Perdigão ${ }^{3}$, J. Marcos Alonso ${ }^{2}$ and Ricardo N. Prado ${ }^{1}$ \\ 1. Electronic Ballast Research Group - GEDRE,PPGEE, Universidade Federal de Santa Maria, RS, Brazil. \\ 2. Universidad de Oviedo, DIEECS, Tecnología Electrónica, Campus de Viesques,Gijón, Spain. \\ 3. Instituto de Telecomunicações, Universidade de Coimbra, DEE, Pólo II, Coimbra, Portugal. \\ rnprado@ieee.org
}

\begin{abstract}
This paper presents a simple configuration, based on the integration of two flyback converters, to supply high intensity discharge (HID) lamps with a low frequency square waveform (LFSW), in order to avoid the occurrence of the acoustic resonance (AR) phenomenon. The proposed topology is compared to a previous presented one. Both topologies integrate two flyback converters in different ways. Losses of both integration modes are compared and advantages are discussed in respect to current and voltage components stress. The proposed electronic ballast presents a high efficiency with a reduced number of components and no over current stress in the shared switch. Experimental results validate both configurations.
\end{abstract}

Keywords - Acoustic resonance, electronic ballasts, HID lamps, integrated converters.

\section{INTRODUCTION}

When High Intensity Discharge (HID) lamps are supplied by high frequency sinusoidal current waveforms, they are susceptible to the occurrence of the acoustic resonance (AR) phenomenon [1]. In literature, many works have studied this phenomenon and different methods have been proposed in order to avoid its occurrence [2] - [6].

The option of supplying the lamp with a low frequency square waveform (LFSW) is presented by many researchers as the most reliable technique [7] - [10]. However, the choice for this method demands electronic ballasts with a high number of power stages, increasing cost and decreasing efficiency.

Usually, in this method, three power stages are necessary. The first one, provides the input power factor correction (PFC), the second is the power control (PC) stage, employed to guarantee the stable lamp operation and the last is the inverter stage, used to alternate the lamp current.

The integration of converters has proven to be a good option to reduce the number of stages and components of the ballast, increasing efficiency and decreasing costs, becoming more attractive to the industry [11][12]. However, when two converters are integrated their shared switch is submitted to some extra current or voltage stress.

In this paper, a novel integrated topology is proposed. Two flyback converters employed in the PFC and PC stages of an electronic ballast are integrated in a single one. This

Manuscript received on 02/05/2008. Revised on 07/07/2008 and 15/09/2008 Accepted by recommendation of the Editor Fernando L. M. Antunes. topology is compared to a previous presented in [8]. The basic difference between both integrations is that the shared switch of the topology proposed in this paper, is submitted to a voltage stress and in the previous one to extra current. The number of components employed in both topologies is the same and their design is similar. Therefore, the topics to be evaluated are the difference of operation, design, calculation of the shared switch drain to source voltage and rms current, and losses presented in both configurations.

\section{INTEGRATED CONFIGURATIONS}

The original circuit and both BiFlyback integrated topologies are presented in Figure 1. The previous one, presented in [8] is called BiFlyback Integrated Ballast with Current Stress (BFIB-CS), and the proposed one is BiFlyback Integrated Ballast with Voltage Stress (BFIB-VS). It can be observed, from Figure 1, that both topologies have the same number of components with similar voltage and current characteristics with the exception of the shared switch $\left(\mathrm{S}_{1}\right)$ and diodes $\mathrm{D}_{5}$ and $\mathrm{D}_{6}$.

In order to understand how the current is distributed among the main switch $\left(\mathrm{S}_{1}\right)$ and diodes $\mathrm{D}_{5}$ and $\mathrm{D}_{6}$ in both configurations, the equivalent circuits and theoretical waveforms are presented in Figure 2. As can be observed in BFIB-CS, the shared switch $\left(\mathrm{S}_{1}\right)$ handles the sum of the currents of both integrated flyback stages. The current through diodes $\mathrm{D}_{5}$ and $\mathrm{D}_{6}$ is equal to $\mathrm{i}_{\mathrm{L} 1}$ and $\mathrm{iF}_{\text {ly } 1}$, respectively. On the other hand, in BFIB-VS, the shared switch $\left(\mathrm{S}_{1}\right)$ only handles the highest current of the two integrated flyback stages in each instant, and diodes $\mathrm{D}_{5}$ and $\mathrm{D}_{6}$ only handle the difference between $\mathrm{i}_{\mathrm{L} 1}$ and $\mathrm{i}_{\mathrm{Fly}}$ c currents. This is the main difference between both topologies.

\section{ANALYSIS OF THE PROPOSED INTEGRATED CIRCUITS}

This section presents the theoretical analysis of both integrated circuits, which includes: design equations of the PC and PFC stages, and the analysis of rms current and drain-to-source voltage in the shared switch.

\section{A. Design of the PC and PFC Stages}

First of all, the characteristics of the PC stage, performed by the flyback converter, are presented. Some considerations are made, in order to analyze this stage: the former converter (PFC stage) is represented as a DC source, $\mathrm{V}_{\mathrm{B}}$; only one of the secondary windings is taken into account, $\mathrm{L}_{\mathrm{Fly} 2-3}$; the 


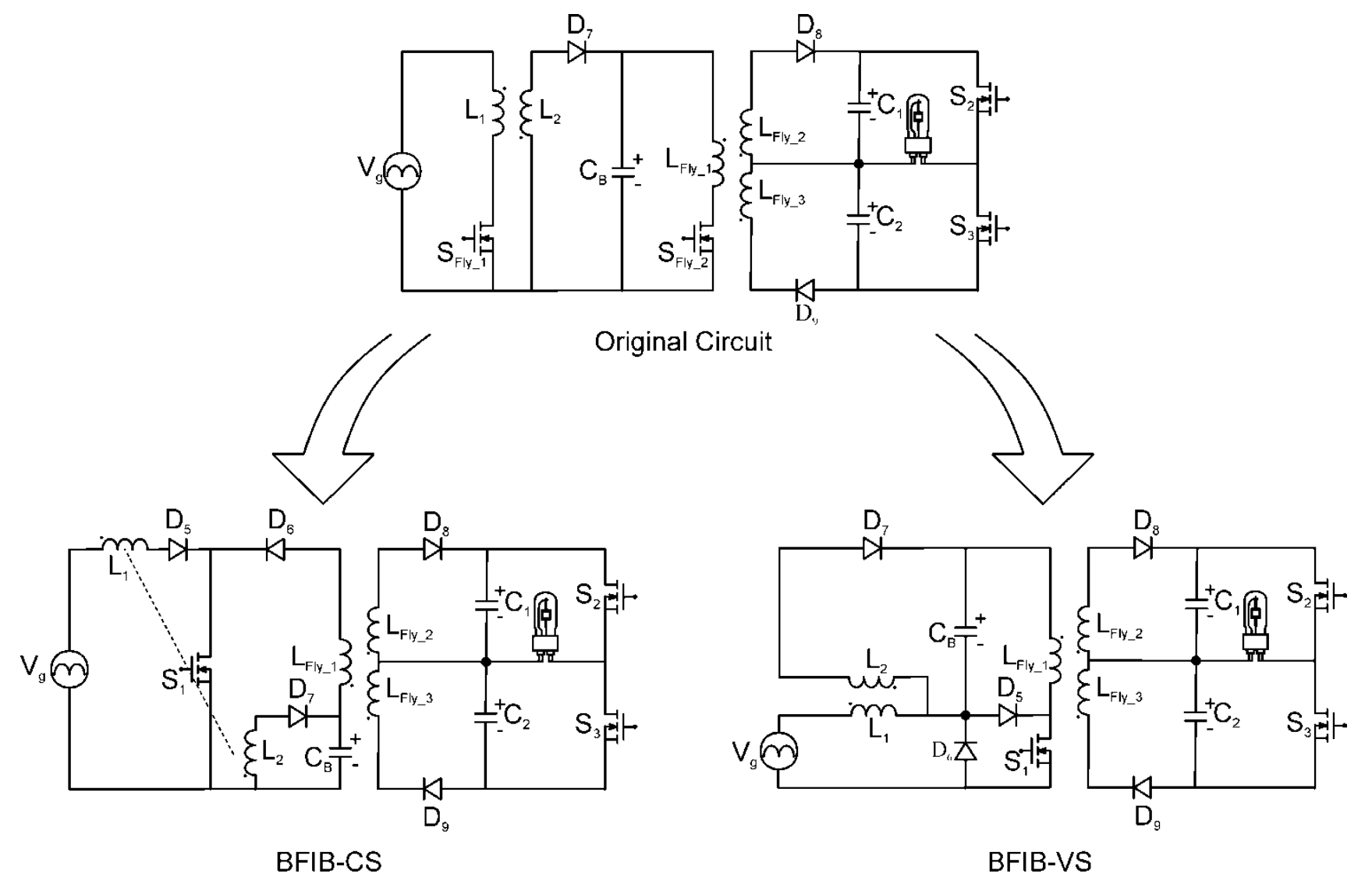

Fig. 1. BiFlyback original circuit and proposed integrated configurations: BFIB-CS and BFIB-VS.

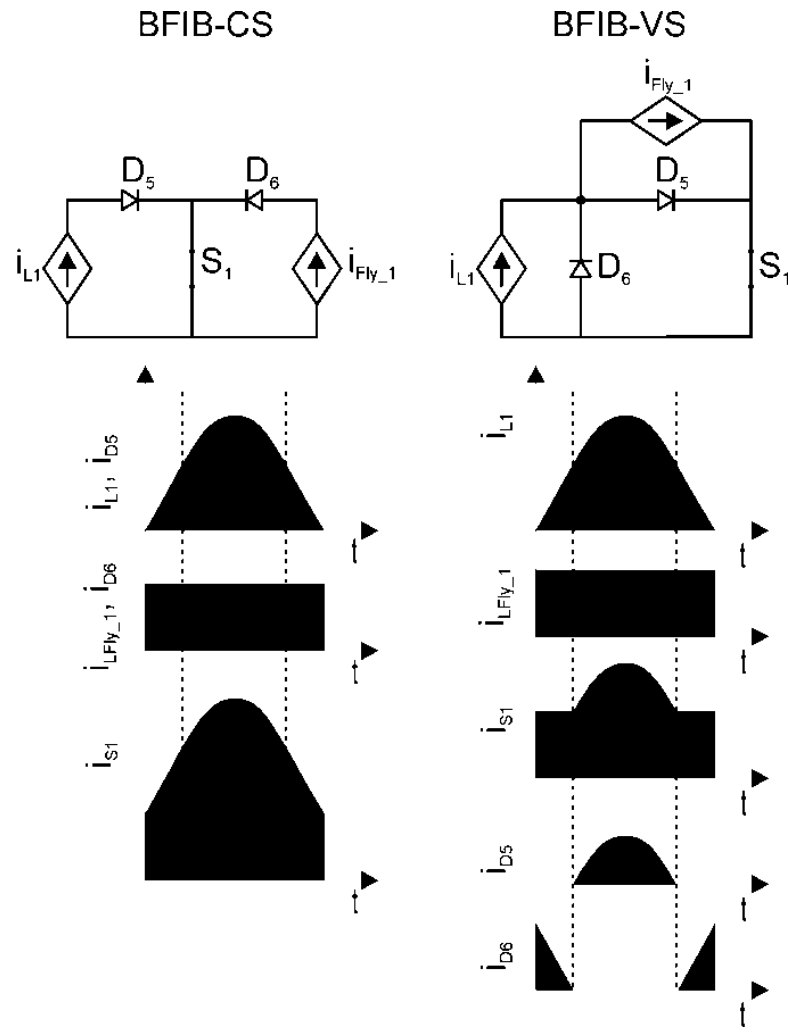

Fig. 2. Equivalent circuit and theoretical waveforms for both configurations. converter must work in discontinuous conduction mode (DCM); and the lamp is considered as a resistance. Then, the equivalent circuit is shown in Figure 3(a) and the main waveforms of primary and secondary winding currents in Figure 3(b).

The analysis of the flyback converter supplied from a DC source is already presented in [9]. Therefore, only the relevant equations are presented in this paper. This converter behaves as a resistance working in DCM, $\mathrm{R}_{\text {Fly }}$, and its equivalent value is shown in (1). The condition to guarantee the DCM operation is shown in (2).

$$
\begin{gathered}
R_{F l y}=\frac{2 \cdot L_{F l y \_} 1}{D^{2} \cdot T_{S}} \\
n_{2}<\frac{(1-D) \cdot V_{L}}{D \cdot V_{B}}
\end{gathered}
$$

Where $\mathrm{L}_{\mathrm{Fly}} 1$ - $\mathrm{PC}$ flyback primary winding inductance, D duty cycle, $\mathrm{T}_{\mathrm{S}}-$ switching period, $\mathrm{n}_{2}-\mathrm{PC}$ flyback turns ratio, $\mathrm{V}_{\mathrm{L}}$ - lamp voltage, and $\mathrm{V}_{\mathrm{B}}-\mathrm{DC}$ bus voltage.

The PFC stage is also performed by a flyback converter working in DCM. This converter is loaded with the PC stage, which can be represented by its equivalent resistance, $\mathrm{R}_{\mathrm{Fly}}$. 


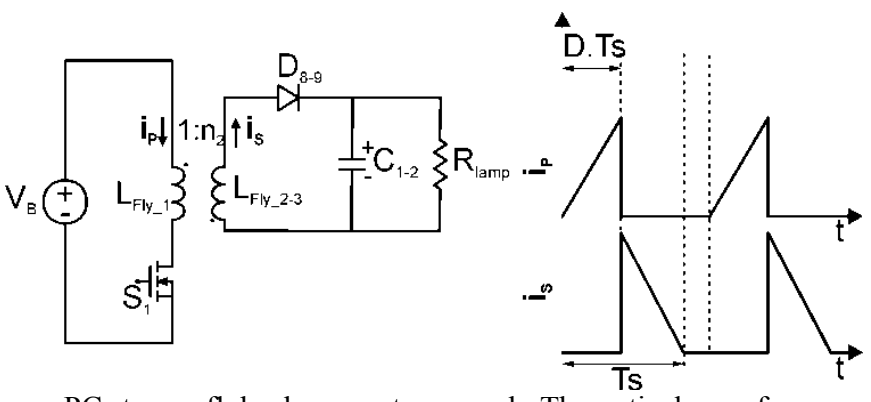

a. PC stage - flyback converter supplied from a DC source.

b. Theoretical waveforms.

Fig. 3. PC stage.

The equivalent circuit is presented in Figure 4. The objective of this analysis is: to define the PFC flyback turns ratio in order to guarantee the DCM operation of the converter, $\mathrm{n}_{1}$; to design the BUS voltage capacitor $\left(\mathrm{C}_{\mathrm{B}}\right)$ according to a desired voltage ripple; and to define all other ballast components. It is important to emphasize that this analysis is common for both configurations, BFIB-VS and BFIB-CS.

In order to simplify the analysis, the following parameters are defined:

$$
\begin{gathered}
m=\frac{V_{G}}{V_{B}} \\
\alpha=\frac{L_{1}}{L_{\text {Fly_1 }}}
\end{gathered}
$$

Where $\mathrm{V}_{\mathrm{G}}$ is the line voltage peak value, and $\mathrm{L}_{1}$ is the primary winding inductance of the PFC flyback.

The flyback turns ratio, which is designed to the boundary between CCM and DCM operation, is shown below, neglecting the BUS voltage ripple.

$$
n_{1}=\frac{(1-D)}{D \cdot m}
$$

The duty cycle, $D$, used to calculate $n_{2}$ in (2) and $n_{1}$ in (5) must be the same, as both flyback converters share the same switch.

As can be seen in Figure 4, the current $i_{B}(t)$, in the PFC stage, is divided between the BUS capacitor, $C_{B}$, and the PC flyback equivalent resistance, $\mathrm{R}_{\mathrm{Fly}}$. Then, considering that the $A C$ component of $i_{B}(t)$ flows only through $C_{B}$ and that the $\mathrm{DC}$ component, $\mathrm{I}_{\mathrm{B}}$, flows only through $\mathrm{R}_{\mathrm{Fly}}$, the BUS voltage, $\mathrm{V}_{\mathrm{B}}$, can be defined as:

$$
V_{B}=I_{B} \cdot R_{F l y}
$$

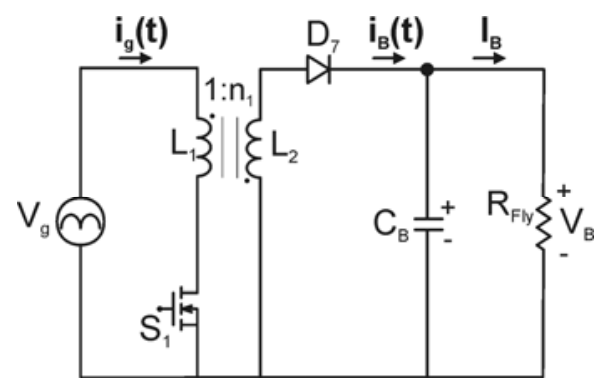

Fig. 4. PFC stage equivalent circuit.
Where,

$$
\begin{gathered}
i_{B}(t)=\frac{V_{G} \cdot m \cdot D^{2} \cdot T_{S}}{2 \cdot L_{1}} \cdot \sin ^{2}(\omega \cdot t), \\
I_{B}=\frac{1}{\pi} \cdot \int_{0}^{\pi} i_{B}(t) \cdot d t=\frac{V_{G} \cdot m \cdot D^{2} \cdot T_{S}}{4 \cdot L_{1}},
\end{gathered}
$$

$\omega$ is the line angular frequency and the time.

Considering (1), (6) and (8), the voltage ratio, $\mathrm{m}$, is defined in function of the inductance ratio, $\alpha$, as presented below.

$$
m=\sqrt{2 \cdot \alpha}
$$

Equation (9) is plotted in Figure 5. This graphic allows to define the inductance ratio, $\alpha$, according to a desired voltage ratio, $\mathrm{m}$. It can be observed that the relation between the bus voltage and the input voltage, $m$, only depends on the inductance ratio $\alpha$.

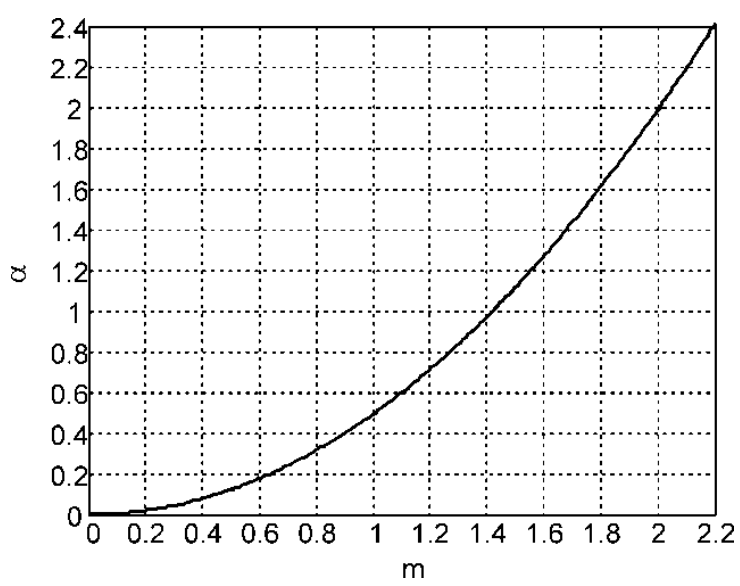

Fig. 5. Inductance ratio $\alpha$ as function of the voltage ratio $\mathrm{m}$.

The equation (10) defines the output power of the analyzed converter, $\mathrm{P}_{\text {out }}$. Besides, $\mathrm{P}_{\text {out }}$ can also be defined as in (11).

$$
\begin{aligned}
& P_{\text {out }}=V_{B} \cdot I_{B} \\
& P_{\text {out }}=\frac{P_{\text {lamp }}}{\eta}
\end{aligned}
$$

Where $\mathrm{P}_{\text {lamp }}$ is the lamp power and $\eta$ the efficiency of the circuit.

Then, using (1), and (10) in (11), a closed equation to calculate $\mathrm{L}_{1}$ is defined.

$$
L_{1}=\frac{\eta \cdot V_{G} \cdot D^{2} \cdot T_{S}}{4 \cdot P_{\text {lamp }}}
$$

Another important issue that must be analyzed before a complete design can be performed is the voltage ripple across the bulk capacitor, $\Delta \mathrm{V}_{\mathrm{B}}$. The peak-to-peak voltage ripple across the bulk capacitor can be calculated through the charge injected into the capacitor $(\Delta \mathrm{Q})$, as follows: 


$$
\Delta V_{B}=\frac{\Delta Q}{C_{B}}=\frac{1}{2 \cdot \omega \cdot C_{B}} \cdot \int_{0}^{\pi}\left|i_{B}(t)-I_{B}\right| \cdot d t
$$

The ripple factor is defined in (14). Therefore, the equation that defines the necessary bus capacitance to limit the ripple below to a determined value is shown in (15).

$$
\begin{gathered}
v=\frac{\Delta V_{B}}{V_{B}} \\
C_{B}=\frac{m^{2} \cdot D^{2}}{8 \cdot \pi \cdot L_{1} \cdot f_{S} \cdot f \cdot v}
\end{gathered}
$$

Where $f_{S}$ is the switching frequency, and $f$ the line frequency.

\section{B. Voltage and Current in the Shared Switch.}

The analysis of maximum drain-to-source voltage and rms current in the shared switch for both circuit configurations is very important, since it is the main difference between the circuits. Besides, this analysis helps to define the suited configuration according to a desired application and, consequently, to choose the appropriate MOSFET to each case. This analysis must be performed for each configuration separately. The theoretical integrated switch current for both analyzed configurations is shown in Figure 6.

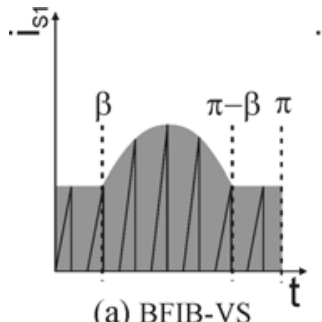

(a) BFIB-VS

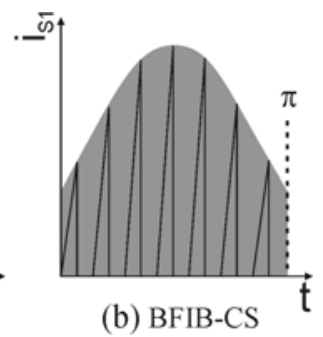

(b) BFIB-CS
Fig. 6. Integrated switch current waveforms for both configurations (not to horizontal scale)

1) BFIB-VS Analysis - As in this configuration only the highest current between both integrated stages is handled by the shared switch, the current through the main switch, $S_{1}$, depends on the conduction angle $\beta$, (Figure 6 (a)). During intervals $[0, \beta]$ and $[\pi-\beta, \pi]$, named PC interval, the switch handles the PC flyback stage current, and during interval $[\beta, \pi-\beta]$, named PFC interval, the switch handles the PFC flyback stage current. The conduction angle, $\beta$, depends on the ratio $\mathrm{m}$, defined in (3):

$$
\beta=\sin ^{-1}\left(\frac{m}{2}\right)
$$

This $\beta$ value is in radians. Thus, the following equation represents it in seconds:

$$
T_{\beta}=\frac{\beta}{\omega}
$$

Therefore, for $\mathrm{m} \leq 2$, the rms current through the main switch, $\mathrm{I}_{\mathrm{rms}} \mathrm{vs}$, can be defined as:

$$
\left.I_{r m S_{-} V S}=\sqrt{\left[\left(I_{P C_{-} V S}\right)^{2}+\left(I_{P F C_{-} V S}\right)^{2}\right.}\right]
$$

Where $\mathrm{I}_{\mathrm{PC}}$ vs is the switch rms current during the $\mathrm{PC}$ interval, and $\mathrm{I}_{\mathrm{PFC}} \mathrm{vs}$ is the switch rms current during the PFC interval, which are defined below:

$$
\begin{aligned}
& I_{P C_{-} V S}=\sqrt{\frac{2}{T} \cdot \sum_{n=1}^{N T_{P C}} \int_{0}^{D . T_{S}}\left(\frac{V_{B} \cdot t}{L_{F y_{-} 1}}\right)^{2} \cdot d t} \\
& I_{P F C_{-} V S}=\sqrt{\frac{2}{T} \cdot \sum_{n=1}^{N T_{P F C}} \int_{0}^{D . T_{S}}\left(\frac{V_{G} \cdot \sin \left[\begin{array}{l}
2 \cdot \pi \cdot f \cdot \\
\left.\left(T_{\beta}+n \cdot T_{S}\right)\right]
\end{array}\right]}{L_{1}}\right)^{2} \cdot d t}
\end{aligned}
$$

Where $\mathrm{T}$ is the line period,

$$
N T_{P C}=\frac{2 . T_{\beta}}{T_{S}}
$$

and

$$
N T_{P F C}=\frac{\pi-2 \cdot \beta}{\omega \cdot T_{S}} .
$$

Therefore, solving the integrals and using (12), equations (23) and (24) can be defined:

$$
\begin{gathered}
\left(I_{P C_{-} V S}\right)^{2}=\frac{8 \cdot N T_{P C} \cdot P_{\text {lamp }}{ }^{2}}{3 \cdot V_{B}^{2} \cdot f_{S} \cdot D \cdot \eta^{2}} \\
\left(I_{P F C_{-} V S}\right)^{2}=\frac{16 \cdot P_{\text {lamp }}{ }^{2}}{3 \cdot V_{G}{ }^{2} \cdot f_{S} \cdot D \cdot \eta^{2}} \cdot \sum_{n=1}^{N T_{P F C}}\left(\sin \left[\begin{array}{l}
2 \cdot \pi \cdot f \cdot \\
\left(T_{\beta}+n \cdot T_{S}\right)
\end{array}\right]\right)^{2}
\end{gathered}
$$

In the case that $m>2\left(V_{B}<V_{\beta}\right)$, the PC stage current is always higher than the PFC stage current in steady state. In this case, the main switch handles only the PC stage current, and its value can be defined as:

$$
I_{r m s_{-} P C_{-} V S}=\frac{2 \cdot P_{\text {lamp }}}{V_{B} \cdot \eta \cdot \sqrt{3 \cdot D}}
$$

Another important parameter to be considered is the maximum drain-to-source voltage in the main switch, $\mathrm{V}_{\mathrm{S}}$ vs. Thus, neglecting the flyback leakage inductance, this parameter can be defined as:

$$
V_{S_{-} V S}=V_{G}+V_{B}+\frac{V_{B}}{n_{1}}+\frac{V_{L}}{n_{2}}
$$

Simplifying this equation:

$$
V_{S_{-} V S}=\frac{V_{G}+V_{B}}{1-D}
$$

2) BFIB-CS Analysis - In opposite to the former analysis, the rms current through the main switch does not depend on 
any conduction angle (Figure 6 (b)), and can be directly defined as:

$$
I_{\text {rms_CS }}=\sqrt{\frac{2}{T} \cdot\left[\sum_{n=1}^{N T} \int_{0}^{D \cdot T_{S}}\left(\begin{array}{l}
\frac{V_{B} \cdot t}{L_{F l y \_} 1}+ \\
\left.\frac{V_{G} \cdot \sin \left[2 \cdot \pi \cdot f \cdot\left(n \cdot T_{S}\right)\right] \cdot t}{L_{1}}\right)^{2}
\end{array}\right]\right.}
$$

Thus, simplifying the equation, the following expression is obtained:

$$
I_{r m s_{-} C S}=\frac{2 \cdot P_{\text {lamp }}}{V_{B} \cdot V_{G} \cdot \eta} \cdot \sqrt{\frac{2}{3 \cdot T \cdot f_{S} \cdot D} \cdot}
$$

Where:

$$
N T=\frac{T}{T_{S}}
$$

The maximum drain-to-source voltage in the main switch in this case, $\mathrm{V}_{\mathrm{S} \text { CS }}$, can be one of the indicated in (31) and (32), whichever is higher. It depends on the projected input and BUS voltage. If $\mathrm{V}_{\mathrm{G}}>\mathrm{V}_{\mathrm{B}}$ the shared switch voltage is calculated using (31), on the other hand, (32) must be used.

$$
\begin{aligned}
& V_{S_{-} C S}=\frac{V_{G}}{1-D} \\
& V_{S_{-} C S}=\frac{V_{B}}{1-D}
\end{aligned}
$$

3) Shared Switch Design - Considering the previous analysis the abacus of Figure 7 for both configurations (BFIB-VS and BFIB-CS) can be build. This abacus makes possible to design the electronic ballast evaluating the shared switch necessary characteristics for each case.

To build this abacus the following parameters have to be defined: mains - $110 \mathrm{Vrms} / 50 \mathrm{~Hz}$; lamp - PHILIPS Master Color CDM-T $35 \mathrm{~W}$, converters switching frequency -80 $\mathrm{kHz}$ and expected electronic ballast efficiency $-90 \%$.

The characteristics of switch voltage and current are plotted in function of $V_{B}$ and $D$, which can be chosen according to the desired MOSFET parameters.

\section{PROJECT EXAMPLE}

Two Electronic ballasts are projected and implemented for an input voltage of $110 \mathrm{~V}, 50 \mathrm{~Hz}$, in order to supply a $35 \mathrm{~W}$ $\mathrm{MH}$ lamp. The ballasts were designed to a bus voltage of 100 V. So, $\mathrm{m}=1.55$ is calculated in (3), and through the graphic of Figure 5 , a relation between the inductances $\alpha=1.2$ is obtained. Once the flyback employed in the PC stage is projected according [5], the input flyback can be designed through the $\alpha$ ratio. The considered switching frequency is $80 \mathrm{kHz}$ and the duty cycle for the steady state operation is around 39\%. The bus capacitor value is calculated in (15) for a maximum bus voltage ripple of $10 \%$.

The projected values and employed components are presented in table I.

TABLE I

Commercial Components

BFIB-CS and BFIB-VS

\begin{tabular}{cc}
\hline $\mathrm{D}_{5}, \mathrm{D}_{6}, \mathrm{D}_{7}, \mathrm{D}_{8}$ and $\mathrm{D}_{9}$ & UF4007 \\
\hline $\mathrm{C}_{\mathrm{B}}$ & $\begin{array}{c}\text { Electrolytic capacitor } \\
150 \mu \mathrm{F} / 160 \mathrm{~V}\end{array}$ \\
\hline $\mathrm{S}_{1}$ & IRFPE50 \\
\hline $\mathrm{S}_{2}$ and $\mathrm{S}_{3}$ & IRF840 \\
\hline $\mathrm{L}_{1}=\mathrm{L}_{2}$ & $\mathrm{NEE}-30 / 15 / 7$ core from Thornton ${ }^{\circledR}$ \\
& $232 \mu \mathrm{H}-44$ winds \\
$\mathrm{L}_{\mathrm{Fly} 1} 1$ & $348 \mu \mathrm{H}-54$ winds \\
$\mathrm{L}_{\mathrm{Fly} 2}=\mathrm{L}_{\mathrm{Fly} 3} 3$ & $\mathrm{NEE}-30 / 15 / 7$ core from Thornton ${ }^{\circledR}$ \\
\hline $\mathrm{C}_{1}=\mathrm{C}_{2}$ & Polypropylene capacitor \\
& $220 \mathrm{nF} / 630 \mathrm{~V}$
\end{tabular}

Through the abacus of Figure 7 the expected peak voltage and rms current across the shared switch can be obtained as shown in Figure 8. However, in the proposed BFIB-VS there is no over current in the shared switch; nevertheless the voltage stress is higher than in the previous presented topology (BFIB-CS).

\section{EXPERIMENTAL RESULTS}

Experimental results shown in Figure 9 and 10 validate BFIB-VS and BFIB-CS integrations. In Figures 9a, 10a and $9 \mathrm{~b}, 10 \mathrm{~b}$ the input and output characteristics of both configurations are presented; the measured input power factor was 0.996. In Figure 9c it can be observed that only the highest current between both flyback stages is handled by the shared switch (BFIB-VS) and not the sum of them as shown in Figure 10c (BFIB-CS). The drain-to-source voltage in both topologies is shown in Figures $9 \mathrm{~d}$ and $10 \mathrm{~d}$ and is in accordance with the previous calculated values.

Figure 11 shows the measured input current harmonics for BFIB-VS configuration. It is in accordance to the IEC61000-3-2 standard limits.

It is important to notice that the input current harmonics and, consequently, the input power factor for both configurations are the same, as the difference between the topologies is located in the circuit connection done across the main switch and diodes $\mathrm{D}_{5}$ and $\mathrm{D}_{6}$, as explained in section II.

\section{LOSSES ANALYSIS}

The main purpose of this section is to compare the losses in the shared switch $\left(\mathrm{S}_{1}\right)$ and diodes $\mathrm{D}_{5}$ and $\mathrm{D}_{6}$, as there is no losses difference in the other components. The shared switch employed for both topologies are the same (IRFPE50), because the drain-to-source voltage $\left(\mathrm{V}_{\mathrm{DS}}\right)$ for this project presents a difference of $164 \mathrm{~V}$, which is not significant to employ different MOSFETS. Losses are studied through simulation and presented in the graphic of Figure 12. The efficiency obtained through experimental results, for the BFIB-VS configuration is $85 \%$ and for the BFIB-CS is $81 \%$. 
BFIB-VS
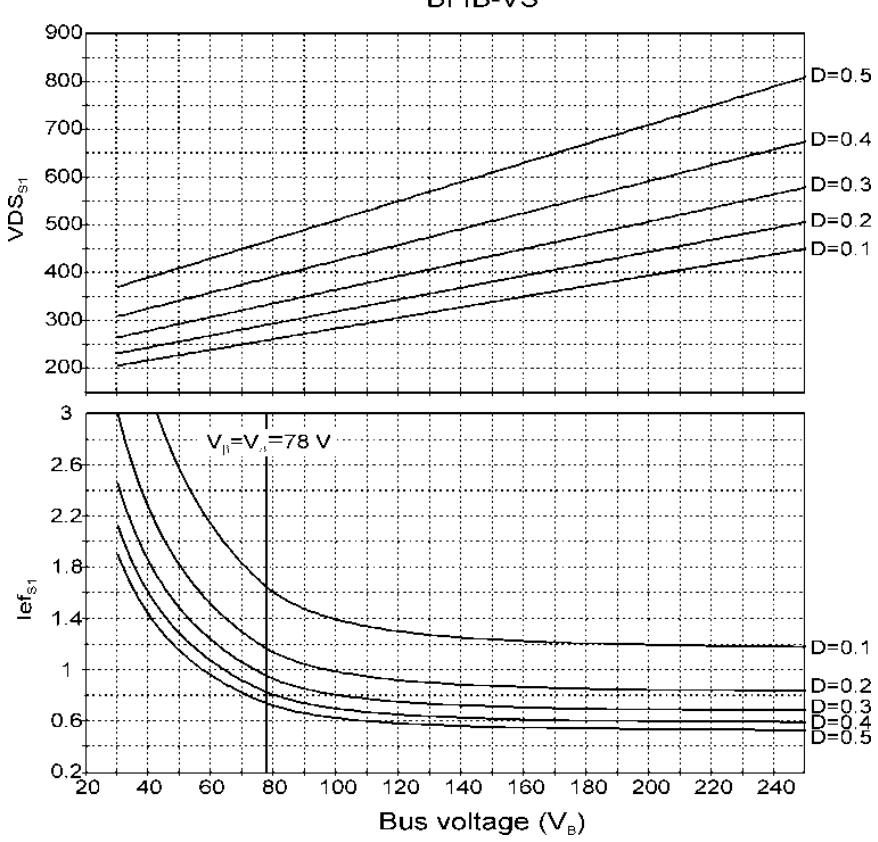

BFIB-CS
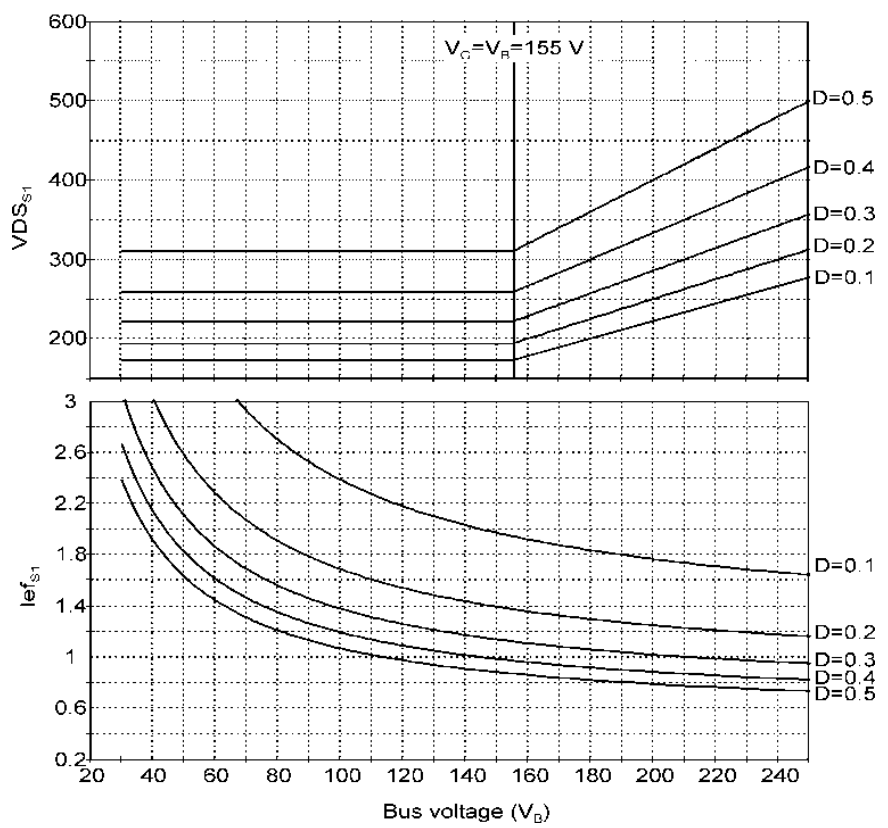

Fig. 7. Integrated switch drain-to-source voltage and rms current characteristic.
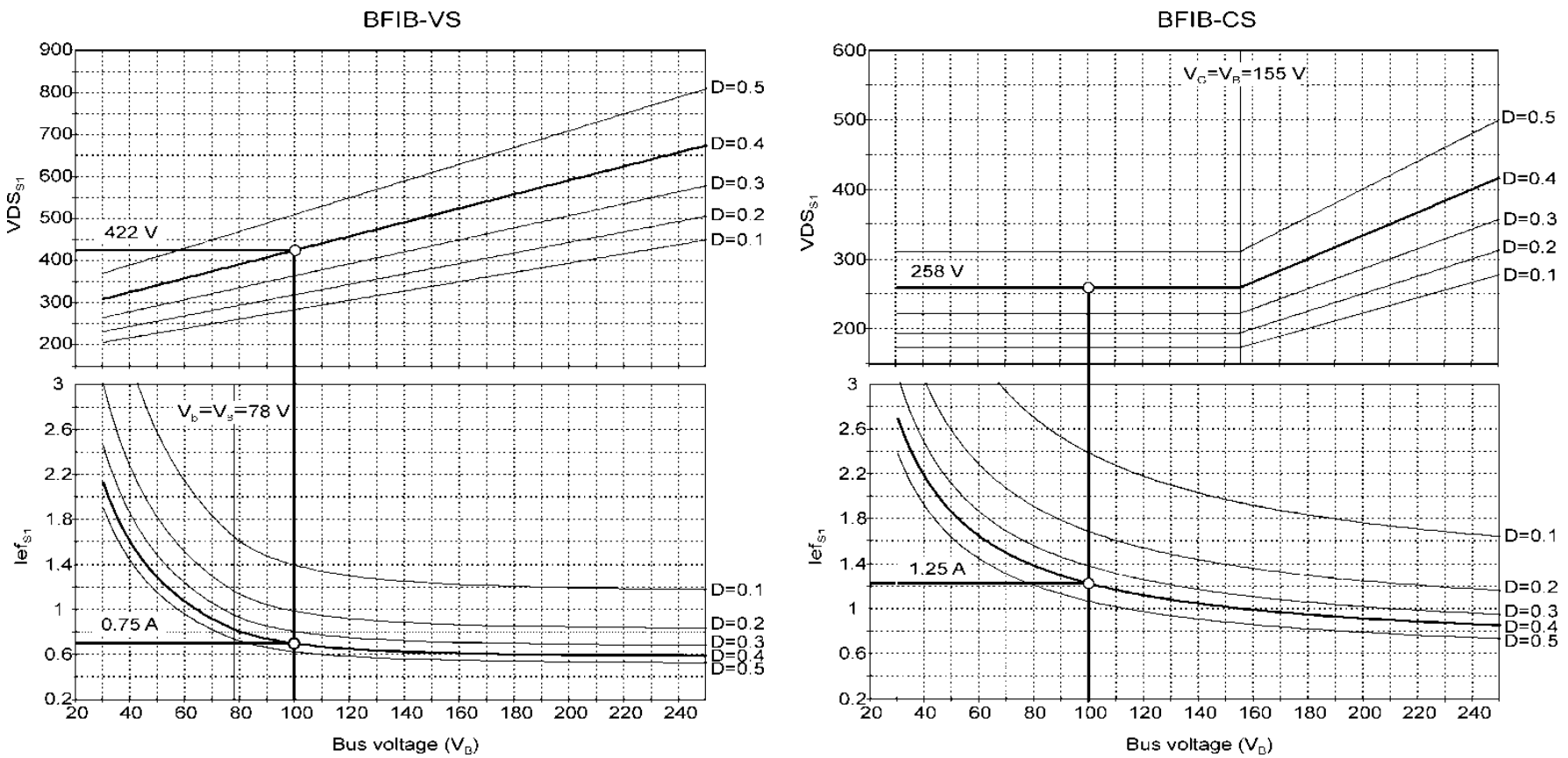

Fig. 8. Defined shared switch drain-to-source voltage and rms current to $\mathrm{V}_{\mathrm{B}}=100 \mathrm{~V}$ and $\mathrm{D}=0.4$.

The lower efficiency of BFIB-CS occurs due to the higher shared switch conduction losses presented by this configuration, as can be seen in Figure 12.

Also, experimental results for both integrations are obtained in [13] for a mains of $220 \mathrm{Vrms} / 60 \mathrm{~Hz}$ to supply an OSRAM Vialox $70 \mathrm{~W}$ HPS lamp. The efficiency obtained in that case for the BFIB-VS configuration is $91.6 \%$ and for the BFIB-CS is $84.5 \%$ employing a COOLMOS SPW17N80C2 in the shared switch.
The results show that increasing the input voltage and the output power the efficiency of both configurations tends to increase, and, as expected the BFIB-VS efficiency is higher than the BFIB-CS configuration.

The maximum power that these integrations may provide to the load, in order to supply different lamp wattages, depends on the limits of the flyback converter working on DCM. This issue is being evaluated and will be presented in a future work. 


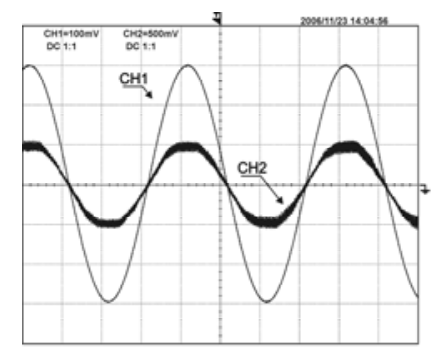

a. Input voltage $(\mathrm{CH} 1-50 \mathrm{~V} / \mathrm{div})$ and current (CH2-500 mA/div), $5 \mathrm{~ms} /$ div.

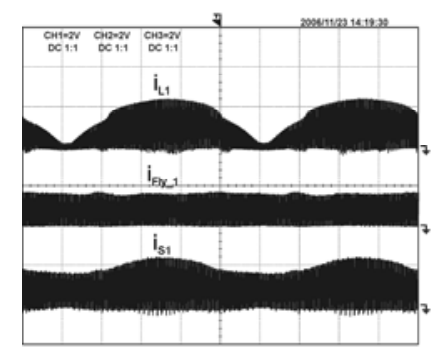

c. Converter currents: PFC stage $\left(\mathrm{i}_{\mathrm{L} 1}-\right.$ $2 \mathrm{~A} /$ div), $\mathrm{PC}$ stage $\left(\mathrm{i}_{\mathrm{Fly}_{-} 1}-2 \mathrm{~A} / \mathrm{div}\right)$ and shared switch $\left(\mathrm{i}_{\mathrm{S} 1}-2 \mathrm{~A} / \mathrm{div}\right), 2$ $\mathrm{ms} /$ div.

Fig. 9. BFIB-VS experimental results.

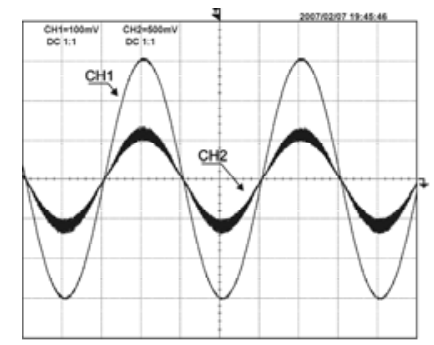

a. Input voltage (CH1-50 V/div) and current (CH2-500 mA/div), $5 \mathrm{~ms} /$ div.

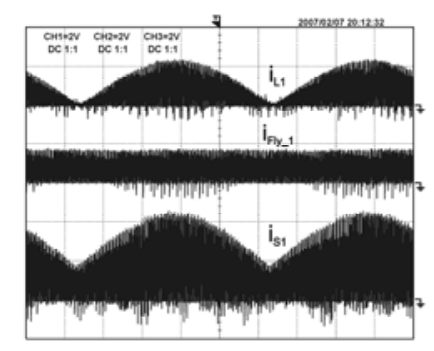

c. Converter currents: PFC stage $\left(i_{\mathrm{L} 1}\right.$ $-2 \mathrm{~A} /$ div), $\mathrm{PC}$ stage $\left(\mathrm{i}_{\mathrm{Fly} \_}-2 \mathrm{~A} / \mathrm{div}\right)$ and shared switch $\left(\mathrm{i}_{\mathrm{S} 1}-2 \mathrm{~A} / \mathrm{div}\right), 2$ ms/div.

Fig. 10. BFIB-CS experimental results

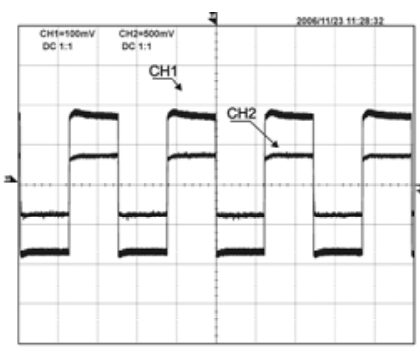

b. Lamp voltage $(\mathrm{CH} 1-50 \mathrm{~V} / \mathrm{div})$ and current (CH2-500 mA/div), 1 $\mathrm{ms} /$ div.

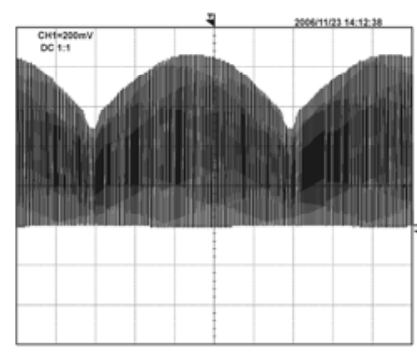

d. Shared switch voltage (CH1$100 \mathrm{~V} /$ div), $2 \mathrm{~ms} /$ div.

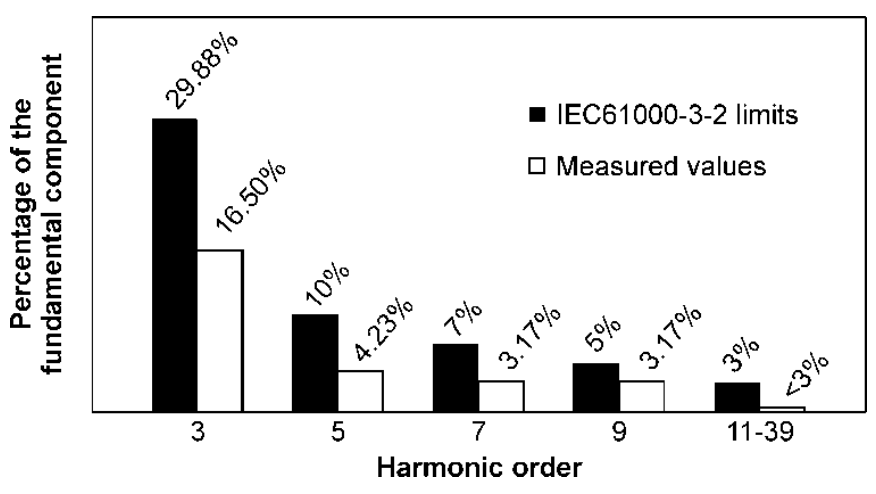

Fig. 11. Measured input current harmonics compared to the IEC61000-3-2 standard limits for the BFIB-VS.

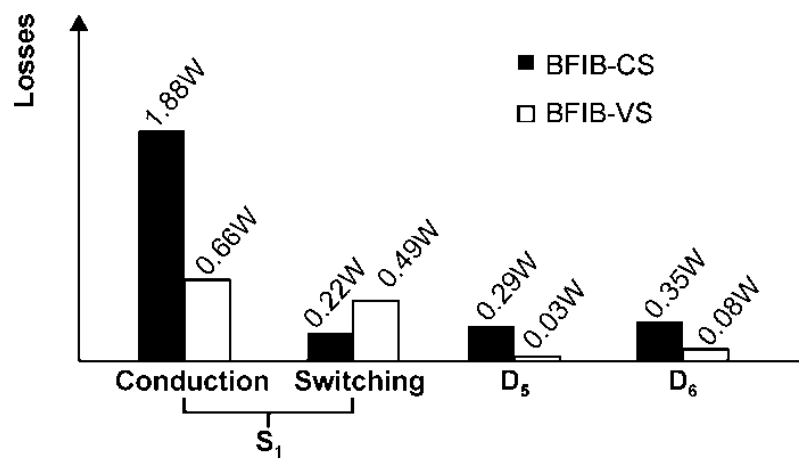

Fig. 12. Comparison between losses in the two electronic ballasts configurations.

\section{CONCLUSION}

The proposed BFIB-VS electronic ballast complies with the industry claims on reducing the product final costs, maintaining high efficiency, input power factor correction and the desired lamp operation. Experimental results validate both configurations and losses comparison show that BFIBVS configuration presents better efficiency than BFIB-CS to supply a $35 \mathrm{~W}$ Metal Halide lamp considering an input voltage of 110 Vrms. The main difference between both topology losses takes place in the shared switch $\left(\mathrm{S}_{1}\right)$. Although the switching losses for the BFIB-VS are higher, the difference of the conduction losses percentage is considerable, leading to a lower overall efficiency of the BFIB-CS configuration in relation to the proposed one, BFIB-VS.

\section{ACKNOWLEDGEMENT}

d. Shared switch voltage (CH1$100 \mathrm{~V} / \mathrm{div}), 2 \mathrm{~ms} / \mathrm{div}$.
This work was supported by CAPES, Brazil under the scholarship process number BEX 12-100/68.

\section{REFERENCES}

[1] J. J. de Groot and J. van Vliet, THE HIGH-PRESSURE SODIUM LAMP. Philips technical library. MacMillan Education, 1986.

[2] M. A. Dalla Costa, J. M. Alonso, J. Ribas, J. Cardesín, and J. García, "Acoustic-Resonance Characterization of Low-Wattage Metal-Halide Lamps.” IEEE Transactions 
on Plasma Science, vol. 35, no. 1, February 2007, pp. 43-58.

[3] M. A. Dalla Costa, J. M. Alonso, E. Lopez, A. J. Calleja, and J. Ribas, "Acoustic Resonance Characterization of Low-Wattage Metal Halide Lamps under LowFrequency Square-Waveform Operation.” Industry Applications Conference (IAS), vol. 3, 2005, pp. 15751580.

[4] J. Garcia-Garcia, J. Cardesín, J. Ribas, A. J. Calleja, M. Rico-Secades, J. M. Alonso, and E. L. Corominas, "Minimization of Acoustic Resonances in HID Lamps: Analysis and Comparison of Power Harmonics Content in High Frequency Non-Resonant Inverters," IEEE Transactions on Power Electronics, vol. 20, Issue 6, Nov. 2005, pp.1467-1478.

[5] J. Garcia, J. Cardesín, J. Ribas, A. J. Calleja, E. L. Corominas, M. Rico-Secades, and J. M. Alonso, "New control strategy in a square-wave inverter for low wattage metal halide lamp supply to avoid acoustic resonances." IEEE Transactions on Power Electronics, vol.21, Issue 1, Jan. 2006, pp. 243-253.

[6] J. Correa, M. Ponce, J. Arau, M. Sanchez, and E. Rodriguez, "Evaluation of Close Loop Digital Control Based in a Microcontroller and Used to Eliminate Acoustic Resonance in HID Lamps," IEEE Power Electronics Specialists Conference (PESC), vol. 1, June 2004, pp. 401-405.

[7] M. Shen, Z. Qian, and F. Z. Peng, "Design of a twostage low-frequency square-wave electronic ballast for HID lamps," IEEE Transaction on Industry Applications, vol. 39, 2003, pp. 424 - 430.

[8] T. B. Marchesan, D. Pappis, R. A. Pinto, A. Campos, R. N. do Prado, "Double-Flyback Half-Bridge electronic ballast to supply HPS lamps," IEEE Industrial Electronics Conference (IECON), November 2005.

[9] M. A. Dalla Costa, J. M. Alonso, J. Garcia, J. Cardesin, "Low-cost electronic ballast to supply MH lamps based on flyback converter," Electronics Letters, vol. 41, $\mathrm{n}^{\mathrm{o}}$ 10, May 2005, pp. 615-616.

[10] M. A. Dalla Costa, J. M. Alonso, J. García, J. Cardesin, M. Rico, "A Novel Low Cost Electronic Ballast to Supply Metal Halide Lamps," IEEE industry applications Society Meeting (IAS), vol. 3, October 2005, pp. 1575-1580.

[11] J. F. Dums, C. B. Nascimento and A, J. Perin, "SingleStage Charge-Pump Voltage-Source Electronic Ballast for a 70 W HPS Lamp," Revista Brasileira de Eletrônica de Potência (SOBRAEP), vol. 12, March 2007, pp. 4351.

[12] G. C. Sincero, A. S. Franciosi and A. Perin, "Reator Eletrônico para Lâmpadas de Vapor de Sódio de Alta Pressão de 250 W com Alto Fator de Potência Utilizando um Conversor CA-CA," Revista Brasileira de Eletrônica de Potência (SOBRAEP), vol. 11, November 2006, pp. 207-214.

[13] T. B. Marchesan, "Integração de Conversores Estáticos Aplicados a Sistemas de Iluminação Pública", Ph.D. tesis in Electrical Engineering (in Portuguese), Federal University of Santa Maria, Brazil, January 2008.

\section{BIOGRAPHIES}

Tiago Bandeira Marchesan was born in Santa Maria, Brazil, in 1980. He received the B.S. in 2003 (with first class honours) and the Ph.D. in 2008, both in electrical engineering from Federal University of Santa Maria, Brazil.

He has been with the electronic Ballast Research Group (GEDRE), as a researcher, since 2000. He is associated professor at the Technology Department of the Regional University of the Northwest of Rio Grande do Sul State.

His research interests include electronic ballasts, high intensity discharge lamps, lighting emitting diodes (LEDs), dimming systems, modeling and simulation of power converters.

Marco A. Dalla Costa was born in Santa Maria, Brazil, in 1978. He received the B.S. and M.Sc. degrees in Electrical Engineering from the Federal University of Santa Maria, Brazil, in 2002 and 2004, and the Ph.D. degree from University of Oviedo, Spain, in 2008.

$\mathrm{He}$ is currently a researcher working on the development of electronic systems for lighting and HID lamp modeling. His research interests include dc/dc converters, PFC stages, dimming systems, high-frequency electronic ballasts, discharge lamp modeling, and electronic starters for HID lamps.

Marina Perdigão received the B.S. and M.Sc. degrees in Electrical Engineering from the University of Coimbra, Portugal, in 2001 and 2004. She is currently working toward her Ph.D degree in University of Oviedo, Spain.

She is a professor at the Engineering Institute of Coimbra since 2002. She is currently a researcher working on the development of electronic systems for a new dimming technology. Her research interests include electronic ballasts, dimming features of fluorescent lamps, DC/DC converters and high intensity discharge lamps.

J. Marcos Alonso received the M.Sc. degree and Ph.D. both in electrical engineering from the University of Oviedo, Spain, in 1990 and 1994 respectively. From 1990 to 1999 he was assistant professor at the Electrical and Electronic Department of the University of Oviedo, where since 1999 he is an Associate Professor.

Dr. Alonso is the primary author for more than 40 journal and international conference papers in power and industrial electronics, and has co-authored more than 100. His research interests include high-frequency electronic ballasts, discharge lamp modeling, power converters for ozone generation, power converters for electrostatic applications, power factor correction topologies and high frequency switching converters. He was the advisor of four Ph.D. Thesis students in the field of power electronics. He is the holder of four Spanish patents with two under review.

Dr. Alonso was awarded with the Early Career Award of the IEEE Industrial Electronics Society in 2006. He received the second prize paper award of the 2005 IEEE Industry Applications Society Meeting, Production and Application of Light Committee. He was also awarded with the IEEE Industrial Electronics Society Meritorious Paper Award for 1996. 
He is an active member of the Institute of Electrical and Electronics Engineers (IEEE), where he usually collaborates as transactions paper reviewer, conference session chairman, among other positions. Since October 2002 he serves as an Associate Editor of the IEEE Transactions on Power Electronics in the field of Lighting Applications. He is also a member of the International Ozone Association (IOA).

Ricardo Nederson do Prado was born in Itapiranga, Brazil, in 1961. He received the B.Sc. degree from the Federal University of Santa Maria, Santa Maria, Brazil, in 1984, and the M.Sc. and Ph.D. degrees from the Federal University of Santa Catarina, Florianópolis, Brazil, in 1987 and 1993, respectively, all in electrical engineering. From 1987 to 1992, he was a Professor in the Electronics Department, Federal University of Minas Gerais, Belo
Horizonte, Brazil. Since 1993, he has been with the Federal University of Santa Maria, Brazil, where he is currently an associate Professor in the Electrical Energy Processing Department. From 2005 to 2006, he was with the Fraunhofer Institute, Germany, as a Post doctoral Research Scholar. He is responsible for the Electronic Ballast Research Group (GEDRE). He has co-authored more than 140 technical papers on electronic ballast. His research directions include high-frequency high-density power converters, fluorescent and high pressure lamps, dimming systems, luminous efficiency, electronic ballasts, LED as a source light and power-factor correction.

Dr. Prado is a Founding Member of the Brazilian Power Electronics Society; He is the Member of the Brazilian Automatic Control Society, and several IEEE societies. 